\title{
Bivariate Analysis of Number of Services to Conception and Days Open in Norwegian Red Using a Censored Threshold-Linear Model
}

\author{
Y. M. Chang, ${ }^{\star 1}$ I. M. Andersen-Ranberg,† B. Heringstad,†‡ D. Gianola, ${ }^{\star} \ddagger$ and G. Klemetsdal‡ \\ *Department of Dairy Science, University of Wisconsin, Madison 53706 \\ †GENO Breeding and A.I. Association, P.O. Box 5003, N-1432 Ås, Norway \\ $\ddagger$ Department of Animal and Aquacultural Sciences, Norwegian University of Life Sciences, \\ P.O. Box 5003, N-1432 Ås, Norway
}

\begin{abstract}
A bivariate censored threshold-linear model was used to study genetic parameters of number of services to conception (STC) and days open (DO) in first-lactation Norwegian Red (NRF) cows. Records of 1,454,916 NRF cows, with a first insemination from 1980 to 2004, were analyzed. It was assumed that every cow had at least a first insemination. The number of inseminations was recorded until a cow conceived or was culled, whichever occurred first. If a cow was culled before conception, it was considered censored at the number of services until culling was recorded. Twenty-one percent of cows were censored for both STC and DO. Using an univariate probit link function for STC, unobserved liabilities to STC and DO were modeled jointly as a linear function of age at first calving, month-year at first calving, herd5 -yr period, sire of cow and residual effects. Heritability of liability to STC and DO was $4 \%$ for each trait. The genetic and residual correlations between STC and DO were 0.77 and 0.68 , respectively. There has been little or no genetic change for DO, whereas STC had favorable genetic and phenotypic trends.
\end{abstract}

Key words: bivariate censored threshold-linear model, services to conception, days open, heritability

\section{INTRODUCTION}

Female fertility is an economically important trait in dairy cattle production. Consequences of reproductive problems are prolonged lactation length, increased number of inseminations, higher veterinary costs, and more involuntary culling. Genetic evaluation of fertility is difficult, mainly because of incomplete data recording and lack of proper statistical methods for handling discrete, skewed, and censored observations. Interval and success or failure traits within some time interval are

Received July 15, 2005.

Accepted October 14, 2005.

${ }^{1}$ Corresponding author: chang@calshp.cals.wisc.edu commonly used for assessing fertility in dairy cattle (Weigel, 2004).

Variation in number of services to conception (STC) reflects variation in female fertility, and the trait gives a measure of pregnancy rate directly (González-Recio et al., 2004). A high STC results in prolonged days open (DO), and increased feeding, insemination, and culling costs, as well as a delay of onset of subsequent lactation. In turn, DO is an interval trait, and a composite measure of time to first insemination and of pregnancy rate (González-Recio and Alenda, 2005); DO can provide information about fertility supplementary to STC. Thus, DO is a widely used trait for assessing female fertility in dairy cattle (Dematawewa and Berger, 1998; VanRaden et al., 2004). However, DO is heavily dependent on management practices, because a longer voluntary waiting period before insemination may be preferred for high-yielding cows (Dekkers et al., 1998). Dematawewa and Berger (1998) found strong positive phenotypic and genetic correlations between days open (restricted to a maximum of $305 \mathrm{~d}$ ) and total number of breedings (varying from 1 to 9) during each lactation using linear animal models. Roxström et al. (2001) reported a genetic correlation (0.73) of days from calving to last insemination with number of inseminations, also using a linear model. Jamrozik et al. (2005) reported genetic correlations of 0.92 and 0.96 between number of services and intervals from first service to conception for first and later lactation cows, respectively.

A concern in genetic analysis of fertility is how to handle cows that do not become pregnant or that are culled with unknown pregnancy status (i.e., censored records). There are few estimates of the genetic correlation between STC and DO probably due to censoring acting on both traits; that is, cows are culled before the next calving with unknown pregnancy status. Ignoring censoring can distort inference and produce biased estimates of genetic parameters (Carriquiry et al., 1987). Loss of information due to incomplete records can be reduced if censoring is considered in genetic analysis.

Survival analysis provides an appropriate manner of dealing with time-to-event traits, and is capable of 
handling censored records for interval traits (Ducrocq and Casella, 1996). A Bayesian linear mixed model analysis of a censored normal distribution (Sorensen et al., 1998) may be an alternative to survival analysis. Likewise, an ordinal threshold model, suitable for ordered categorical traits, can accommodate situations in which discrete variables are censored at their last observed realization, as is the case with STC.

Female fertility has been included in the total merit index for Norwegian Red (NRF) since 1972. At present, 56-d nonreturn rate in heifers and in first-lactation cows is used for selection of NRF sires for fertility; their relative weight in the total merit index is $15 \%$. Fertility is a complex trait and a challenge is to decide which traits are to be considered in genetic evaluation for fertility, due to low heritability, and to its unfavorable correlation with milk yield. New methods of handling fertility traits other than nonreturn rates should be investigated.

Our objectives were to infer heritability coefficients and the genetic correlation between STC and DO using a bivariate censored threshold-linear model, and to estimate genetic change for these traits in NRF.

\section{MATERIALS AND METHODS}

\section{Data}

Records of STC and DO from 1,454,916 first-lactation $\mathrm{NRF}$ cows with calving and first insemination data from 1980 to 2004 were included. All cows had information on both traits. First- and second-crop daughters of the 3,184 NRF sires that were progeny tested after 1980 were included. If a cow had documented veterinary treatment of fertility disorders, the record was discarded, because these treatments could adversely affect genetic evaluation. Age at first calving was between 83 and $174 \mathrm{wk}$, and the period from calving to the time data were collected (February 1, 2005) had to be at least 365 d. Each herd-5-yr class had at least 5 records. Herd5 -yr classes were defined instead of herd-year-season or herd-year because of the large number of cases in which small herds had only a single record per year on season. Double insemination was defined as a new insemination occurring 0 to $5 \mathrm{~d}$ after first insemination. For each cow, all services in first lactation other than double inseminations were counted. The STC were assigned to 5 categories ( 1 to 5 ), with 5 or more inseminations grouped together as one category. Number of DO was the number of days from calving to conception. Cows without a second calving were censored for both traits, and censoring rate was $21 \%$. A total of 3,513 males were included in the sire pedigree file.

\section{Statistical Models}

Censored Linear Model. Survival analysis has been applied in animal breeding because of its ability to handle censored records in the context of time-to-event response variables. An alternative is a mixed-effects model analysis of a censored normal distribution (Carriquiry et al., 1987; Sorensen et al., 1998; Guo et al., 2001). The linear mixed-effects model may be written as:

$$
y_{i}=x_{i}^{\prime} \beta+z_{h, i}^{\prime} \mathbf{h}+z_{s, i}^{\prime} \mathbf{s}+e_{i}
$$

where $y_{i}$ is the observed (noncensored record) of cow $i$; $x_{i}, z_{h, j}$ and $z_{s, j}$ are incidence vectors related to location vectors $\boldsymbol{\beta}$ (age and month-year of first calving effects), $\mathbf{h}$ (herd-5-yr effects) and $\mathbf{s}$ (sire transmitting abilities), and $e_{i}$ is the residual. Unobserved responses for censored records can be augmented using a truncated normal process as

$$
\tilde{y}_{c} \sim N\left(x_{c}^{\prime} \beta+z_{h, c}^{\prime} \mathbf{h}+z_{s, c}^{\prime} \mathbf{s}, \sigma_{c}^{2}\right) \mathrm{I}\left(y_{c}, \infty\right),
$$

where $y_{c}$ is the observed censoring time, such that the augmented values are larger than the censoring point. This approach does not accommodate time-dependent covariates, but retains the logic of the infinitesimal model of quantitative genetics in its entirety.

Censored Threshold Model. The threshold model postulates a mixed effect model in the scale of a latent variable, liability $(\lambda)$, for each observation (Gianola, 1982; Gianola and Foulley, 1983). The observation takes the value $\mathrm{j}$ only if $\lambda$ is greater than or equal to $\mathrm{T}_{j-1}$ and smaller than $\mathrm{T}_{j}$, where $\mathrm{T}_{j-1}$ and $\mathrm{T}_{j}$ are unknown thresholds. The probability model can be written as:

$$
\begin{aligned}
\operatorname{Prob}\left(y_{i}=\right. & j \mid \beta, \mathbf{h}, \mathbf{s}, \mathbf{T})=\Phi\left[\mathrm{T}_{j}-\left(x_{i} \beta+z_{h, i} \mathbf{h}+z_{s, i} \mathbf{s}\right)\right] \\
& -\Phi\left[\mathrm{T}_{j-1}-\left(x_{i} \beta+z_{h, i} \mathbf{h}+z_{s, i} \mathbf{s}\right)\right]
\end{aligned}
$$

where $j=1,2, \ldots, \mathrm{J}$ indexing the category in which the observation belongs; $\Phi(\cdot)$ is the standard cumulative normal distribution function, and $\mathbf{T}=\left[\mathrm{T}_{0}, \mathrm{~T}_{1}, \mathrm{~T}_{2}, \ldots, \mathrm{T}_{\mathrm{J}}\right]^{\prime}$ is the vector of unknown thresholds. The thresholds must satisfy $-\infty=\mathrm{T}_{0} \leq \mathrm{T}_{1} \leq \mathrm{T}_{2} \leq \cdots, \leq \mathrm{T}_{\mathrm{J}}=\infty$. The first threshold $\mathrm{T}_{1}$ is set to zero, because the parameter cannot be identified in a probit analysis.

This concept accommodates situations in which records are censored at the last observed point. If an observation is censored at the $j$ th insemination, and its status is not pregnant, then its corresponding liability must be larger than $T_{j}$. The probability that the observation is censored at the $j$ th category is: 


$$
\begin{gathered}
\operatorname{Prob}\left(y_{i}=j, \text { censored } \mid \beta, \mathbf{h}, \mathbf{s}, \mathrm{T}\right)= \\
1-\Phi\left[\mathrm{T}_{j}-\left(x_{i}^{\prime} \beta+z_{h, i}^{\prime} \mathbf{h}+z_{s, i}^{\prime} \mathbf{s}\right)\right] .
\end{gathered}
$$

The joint probability of $\mathrm{N}$ noncensored and censored data, given the location effects and the thresholds, is

$$
\begin{gathered}
\operatorname{Prob}(\mathbf{y} \mid \beta, \mathbf{h}, \mathbf{s}, \mathbf{T}, \boldsymbol{\delta})=\prod_{i=1}^{N}\left\{\Phi \left[\mathrm{~T}_{y_{i}}\right.\right. \\
\left.-\left(x_{i}^{\prime} \beta+z_{h, i}^{\prime} \mathbf{h}+z_{s, i}^{\prime} \mathbf{s}\right)\right]-\Phi\left[\mathrm{T}_{y_{i}-1}\right. \\
\left.\left.-\left(x_{i}^{\prime} \beta+z_{h, i}^{\prime} \mathbf{h}+z_{s, i}^{\prime} \mathbf{s}\right)\right]\right\}^{1-\delta_{i}} \\
\left\{1-\Phi\left[\mathrm{T}_{y_{i}-1}-\left(x_{i}^{\prime} \beta+z_{h, i}^{\prime} \mathbf{h}+z_{s, i}^{\prime} \mathbf{s}\right)\right]\right\}^{\delta_{i}}
\end{gathered}
$$

where $\delta$ is the vector of censoring indicators; $\delta_{i}=0$ if a record is not censored and 1 otherwise.

Bivariate Censored Threshold-Linear Model. A Bayesian bivariate model for an ordinal categorical trait and a Gaussian trait (Foulley et al., 1983), with allowance of censored records for the 2 traits, was fitted:

$$
\left[\begin{array}{c}
\lambda \\
\mathbf{y}_{o} \\
\tilde{\mathbf{y}}_{c}
\end{array}\right]=\mathbf{X} \beta+\mathbf{Z}_{h} \mathbf{h}+\mathbf{Z}_{s} \mathbf{s}+\mathbf{e}
$$

where $\lambda$ is the vector of unobserved liabilities to STC, and $\mathbf{y}_{o}$ and $\tilde{\mathbf{y}}_{c}$ are vectors of observed and augmented censored records for DO, respectively. If a cow was censored and confirmed nonpregnant, its augmented DO must be larger than the interval of calving to last insemination plus $21 \mathrm{~d}$. The vector $\boldsymbol{\beta}$ included effects of age at first calving in weeks (92 levels, ranging from 80 to $171 \mathrm{wk}$ ) and of month-year at first calving (295 levels), specific to each trait. Further, h contained herd-5-yr effects (81,736 levels), s was the vector of sire transmitting abilities (3,513 levels), and $\mathbf{e}$ was the vector of residuals for the 2 traits; $\mathbf{X}, \mathbf{Z}_{\mathrm{h}}$, and $\mathbf{Z}_{\mathrm{s}}$ are incidence matrices.

Residuals for the 2 traits were assumed correlated within cows and independent between cows as:

$$
\left[\begin{array}{l}
\mathbf{e}_{1} \\
\mathbf{e}_{2}
\end{array}\right] \sim N(\mathbf{0}, \mathbf{R} \otimes \mathbf{I})
$$

where $\mathbf{R}=\left[\begin{array}{cc}1 & \sigma_{e 12} \\ \sigma_{e 12} & \sigma_{e 2}^{2}\end{array}\right]$ is the residual (co)variance matrix and $\mathbf{I}$ is an identity matrix. The residual variance of liability to STC was set equal to $1 ; \sigma_{e 2}^{2}$ is the residual variance of $\mathrm{DO}$ and $\sigma_{e 12}$ is the residual covariance between liability to STC and DO.
Bounded uniform priors were assigned to each of the elements of $\beta$ as $\beta \sim U\left(\beta_{\min }, \beta_{\max }\right)$ with $\beta_{\min }=-9999$ and $\beta_{\max }=9999$. A multivariate normal prior was used for herd-5-yr effects as

$$
\left[\begin{array}{l}
\mathbf{h}_{1} \\
\mathbf{h}_{2}
\end{array}\right] \sim N(\mathbf{0}, \mathbf{H} \otimes \mathbf{I})
$$

where $\mathbf{H}=\left[\begin{array}{cc}\sigma_{h 1}^{2} & \sigma_{h 12} \\ \sigma_{h 12} & \sigma_{h 2}^{2}\end{array}\right]$ is the $2 \times 2$ (co)variance matrix between herd-5-yr effects for the 2 traits. Effects of different herd-5-years were assumed to be independent, a priori. The vector of sire effects was assigned the multivariate normal prior distribution:

$$
\left[\begin{array}{l}
\mathbf{s}_{1} \\
\mathbf{s}_{2}
\end{array}\right] \sim N(\mathbf{0}, \mathbf{G} \otimes \mathbf{A})
$$

where $\mathbf{G}\left[\begin{array}{cc}\sigma_{s 1}^{2} & \sigma_{s 12} \\ \sigma_{s 12} & \sigma_{s 2}^{2}\end{array}\right]$ is the $2 \times 2$ (co)variance matrix between sire transmitting abilities, and $\mathbf{A}$ is the additive relationship matrix between male ancestors. Independent inverse Wishart prior distributions were used for matrices $\mathbf{H}$ and $\mathbf{G}$ as

$$
\begin{aligned}
& \mathbf{H} \sim I W\left(v_{h}, \mathbf{V}_{h}\right) \\
& \mathbf{G} \sim I W\left(v_{g}, \mathbf{V}_{g}\right)
\end{aligned}
$$

where $v_{\mathrm{h}}=v_{\mathrm{g}}=4$ are the degrees of freedom parameters, and $\mathbf{V}_{\mathrm{h}}$ and $\mathbf{V}_{\mathrm{g}}$ are scale matrices with $\mathbf{V}_{\mathrm{h}}=\left[\begin{array}{cc}0.1 & 0 \\ 0 & 200\end{array}\right]$ and $\mathbf{V}_{\mathrm{g}}=\left[\begin{array}{cc}0.05 & 0 \\ 0 & 20\end{array}\right]$. A scaled inverse $\chi^{2}$ prior distribution was assigned to the residual variance of DO

$$
\sigma_{e 2}^{2} \sim v_{e 2} s_{e 2}^{2} \chi^{-2}\left(v_{e 2}, s_{e 2}^{2}\right)
$$

where $v_{e 2}=3$ and $s_{e 2}^{2}$ are the degrees of freedom and scale parameter, respectively. A bounded uniform prior was used for the residual covariance between STC and DO as

$$
\sigma_{e 12} \mid \sigma_{e 2}^{2} \sim U\left(-\sigma_{e 2}, \sigma_{e 2}\right)
$$

Because we fixed the first threshold to 0 , the rest of the J-2 thresholds associated with the $\mathrm{J}$ categories were assumed to be distributed as order statistics from a uniform distribution with the restriction $0 \leq \mathrm{T}_{2} \leq \cdots \leq$ $\mathrm{T}_{\mathrm{J}-1}$. 
Table 1. Distribution of pregnant and censored cows in categories of number of services to conception (STC) with means \pm standard deviations for days open (DO) in parentheses

\begin{tabular}{lrrrr}
\hline STC & \multicolumn{2}{c}{ Pregnant cows } & \multicolumn{2}{c}{ Censored cows $^{1}$} \\
\hline 1 & 730,348 & $(68.39 \pm 30.56)$ & 155,408 & $(74.49 \pm 36.73)$ \\
2 & 287,664 & $(103.64 \pm 41.53)$ & 90,195 & $(116.49 \pm 48.53)$ \\
3 & 92,494 & $(134.17 \pm 46.16)$ & 41,994 & $(145.09 \pm 50.44)$ \\
4 & 26,340 & $(162.13 \pm 49.58)$ & 15,826 & $(169.24 \pm 51.18)$ \\
$\geq 5$ & 8,065 & $(194.18 \pm 53.30)$ & 6,582 & $(199.86 \pm 52.84)$ \\
\hline
\end{tabular}

${ }^{1} \mathrm{STC}$ and DO for censored cows were the total number of inseminations and days from calving to last insemination, respectively.

Draws from posterior distributions were obtained using a Gibbs sampler, after augmentation of the joint posterior density with unobserved liabilities to STC and censored DO (Sorensen et al., 1995; Sorensen and Gianola, 2002). The thresholds can be sampled from truncated uniform distribution as $\mathrm{U}\left[\max \left(\lambda_{\mathrm{j}-1}\right), \min \left(\lambda_{\mathrm{j}}\right)\right]$, as described in Sorensen and Gianola (2002), where $\max \left(\lambda_{\mathrm{j}-1}\right)$ is the maximum of all liabilities falling in category $\mathrm{j}-1$, and $\min \left(\lambda_{\mathrm{j}}\right)$ is the minimum of all liabilities falling in category $j$. However, this method of sampling the thresholds has been shown to experience slow convergence in some cases (Kizilkaya et al., 2003). The method of Albert and Chib (1997) was used for sampling thresholds, where a log transformation of the thresholds was adopted as

$$
\alpha_{1}=\log \left(\mathrm{T}_{1}\right) \text { and } \alpha_{j}=\log \left(\mathrm{T}_{j}-\mathrm{T}_{j-1}\right),
$$

where $j=2, \ldots, \mathrm{J}-1$. Thresholds can be obtained as

$$
\mathrm{T}_{j}=\sum_{i=1}^{j} \exp \left(\alpha_{i}\right), 1 \leq j \leq \mathrm{J}-1 .
$$

Note that $\alpha_{j}$ does not have any constraints on order, as is the case for the standard parameterization of thresholds. The first threshold $\mathrm{T}_{1}$ was fixed at zero, and other thresholds were obtained indirectly through $\alpha$ 's. A Metropolis algorithm was used to obtain each of the $\alpha$ 's by sampling from a normal proposal distribution with its mean equal to the value from previous iteration and standard deviation of 0.002 .

Convergence Diagnostics. The method of Raftery and Lewis (1992) and visual inspections of trace plots were used to assess the number of iterations and burnin length required. A single long chain of 100,000 iterations was run, and the initial 10,000 samples were discarded as burn in. Inferences were based on the resulting 90,000 samples. The acceptance rate for the Metropolis algorithm was $30 \%$.

\section{RESULTS AND DISCUSSION}

Censoring rate was $21 \%$ for both STC and DO. The distribution of cows over STC categories and their mean

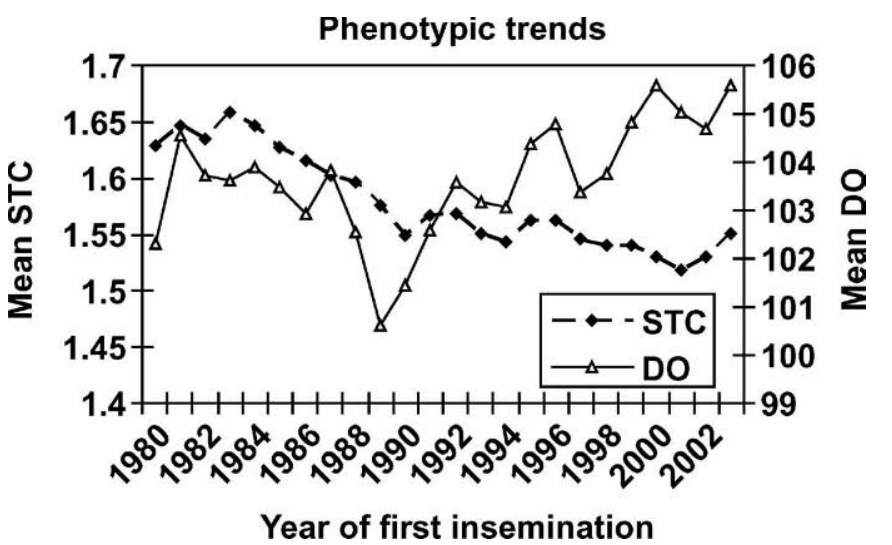

Figure 1. Phenotypic changes of number of services to conception (STC) and days open (DO) in first-lactation Norwegian Red cows, given as phenotypic means by year of first insemination of daughters.

DO are in Table 1. About 64 and $25 \%$ of the pregnant cows had 1 and 2 inseminations, respectively. Number of DO increased with STC, and censored cows had more DO than noncensored cows. Mean DO increased about $4 \mathrm{~d}$ over $20 \mathrm{yr}$, whereas STC had a mean decrease of about 0.1 services (Figure 1 ). The estimated thresholds were $0.83,1.46$, and 1.99 for $\mathrm{T}_{2}, \mathrm{~T}_{3}$, and $\mathrm{T}_{4}$, respectively.

Posterior distributions of sire variances of liability to STC and DO were sharp and symmetric (results not shown). Their posterior means were 0.0096 and 26.92, respectively, as given in Table 2. Posterior distributions of within-herd heritability of liability to STC, of DO, and of the genetic correlation were symmetric and sharp, as shown in Figure 2. Posterior means and standard deviations of variance components, heritabilities, and correlations between STC and DO are in Table 2. Low heritabilities, $4 \%$, were found for both traits, which is consistent with previous fertility studies in NRF (Andersen-Ranberg et al., 2005a,b).

Wall et al. (2003) reported a heritability of 0.02 for both 56-d nonreturn and number of inseminations per

Table 2. Posterior means (standard deviations) of variance components, heritabilities, and genetic, herd-5-yr, and residual correlations between number of services to conception (STC) and days open (DO)

\begin{tabular}{llc}
\hline Parameter & STC & DO \\
\hline Sire variance, $\sigma_{s}^{2}$ & $0.0096(0.0005)$ & $26.92(1.13)$ \\
Herd-5-yr variance, $\sigma_{h}^{2}$ & $0.0837(0.0022)$ & $304.24(2.66)$ \\
Residual variance, $\sigma_{e}^{2}$ & 1 & $2,559.75(11.54)$ \\
Heritability, ${ }^{2} h^{2}$ & $0.04(0.0019)$ & $0.04(0.0017)$ \\
Heritability, ${ }^{2} h^{2}$ & $0.03(0.0017)$ & $0.04(0.0015)$ \\
Genetic correlation & $0.77(0.0142)$ \\
Herd-5-yr correlation & $0.43(0.0058)$ \\
Residual correlation & $0.68(0.0011)$ \\
\hline${ }^{1} h^{2}=4 \sigma_{s}^{2} /\left(\sigma_{s}^{2}+\sigma_{e}^{2}\right)$. & \\
${ }^{2} h^{2}=4 \sigma_{s}^{2} /\left(\sigma_{h}^{2}+\sigma_{s}^{2}+\sigma_{e}^{2}\right)$. &
\end{tabular}

Journal of Dairy Science Vol. 89 No. 2, 2006 
(a)

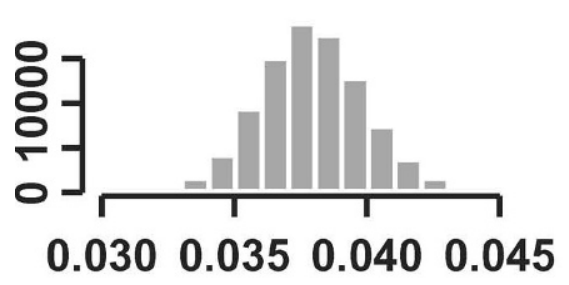

(c)

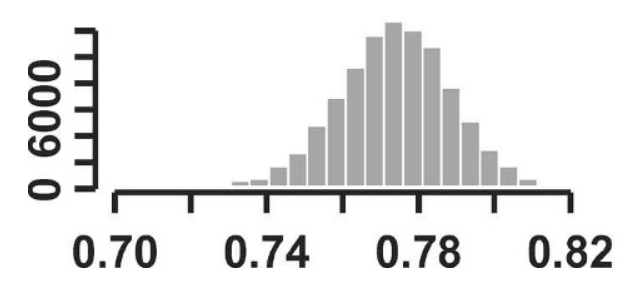

(b)

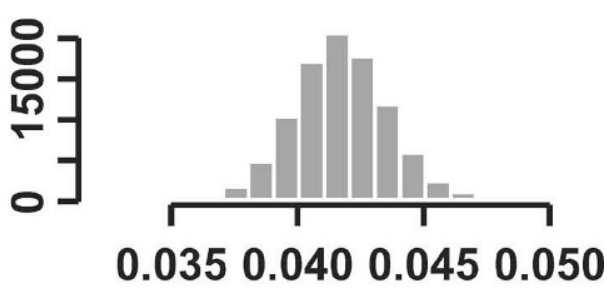

(d)

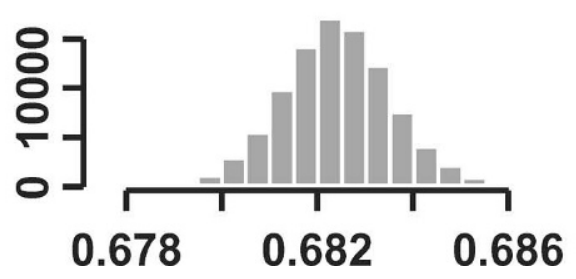

Figure 2. Posterior distributions of a) heritability of liability to services to conception (STC); b) heritability of days open (DO); c) genetic; and d) residual correlations between number of STC and DO.

conception, and a heritability of 0.04 for days to first service. González-Recio et al. (2005) found that heritability of liability to STC ranged between 0.038 and 0.050 using ordinal censored threshold and sequential threshold models. Weller and Ezra (2004) studied female fertility as the inverse of the number of inseminations to conception in Israeli Holstein dairy cattle using a linear animal model, and found heritabilities ranging between 0.02 and 0.03 . Veerkamp et al. (2001) reported a heritability of 0.03 for STC using a linear model. Fitting a negative binomial model, Tempelman and Gianola (1999) estimated a heritability of 0.02. Our results are consistent with published values, although, in general, studies using threshold models tend to give a slightly larger heritability of STC.

Dematawewa and Berger (1998) reported a heritability estimate of 0.04 for DO using a linear animal model. Restricting DO to be between 50 and $250 \mathrm{~d}$, VanRaden et al. (2004) found a heritability of 0.037 for DO in US Holsteins. Oseni et al. (2004) estimated heritability of DO between 0.03 and 0.06 in US Holsteins with different editing criteria, and concluded that DO was strongly influenced by management protocols.

Posterior means of herd-5-yr variance were 0.08 and 304.24 for STC and DO, respectively, which were about 8 and $12 \%$ of their corresponding residual variances. This suggests similar management practices between herds. The herd-5-yr correlation between STC and DO was 0.43 with the posterior standard deviation being 0.006. Andersen-Ranberg et al. (2005a) estimated a herd-year variance of 0.007 for 56 -d nonreturn rate, and of 155.22 for interval from calving to first insemination in first-lactation NRF cows using linear models. Using a bivariate threshold-linear model, the estimated herd variance for 56-d nonreturn rate ranged between 0.047 and 0.055 , and from 117.73 to 118.96 for interval from calving to first service (Andersen-Ranberg et al., 2005b).

Averill et al. (2004) estimated a between-service sires variance of 0.009 using a longitudinal Bayesian threshold analysis of the 3 first insemination events. A service sire variance of 0.013 was estimated from a threshold model for conception rate in French Holstein cattle by Boichard and Manfredi (1994). Andersen-Ranberg et al. (2003) found that service sire had little effect on variance component estimates or on estimates of genetic change in NRF heifers. Service sire was not included in our study because there was no obvious way of incorporating time-dependent service sire effects in an ordinal threshold model. An alternative is to include only effects of first service sire in the model. GonzálezRecio et al. (2005) reported a first-service sire variance of 0.021 for STC using an ordinal censored threshold model in Spanish cows. Tempelman and Gianola (1999) estimated a first-service sire variance ranging between 0.011 and 0.057 using negative binomial models.

The effect of age at first calving on STC and DO are shown in Figure 3. Effects of age at first calving on DO decreased until 25 mo of age, and then increased to around 30 mo of age. The effects of age on DO remained 


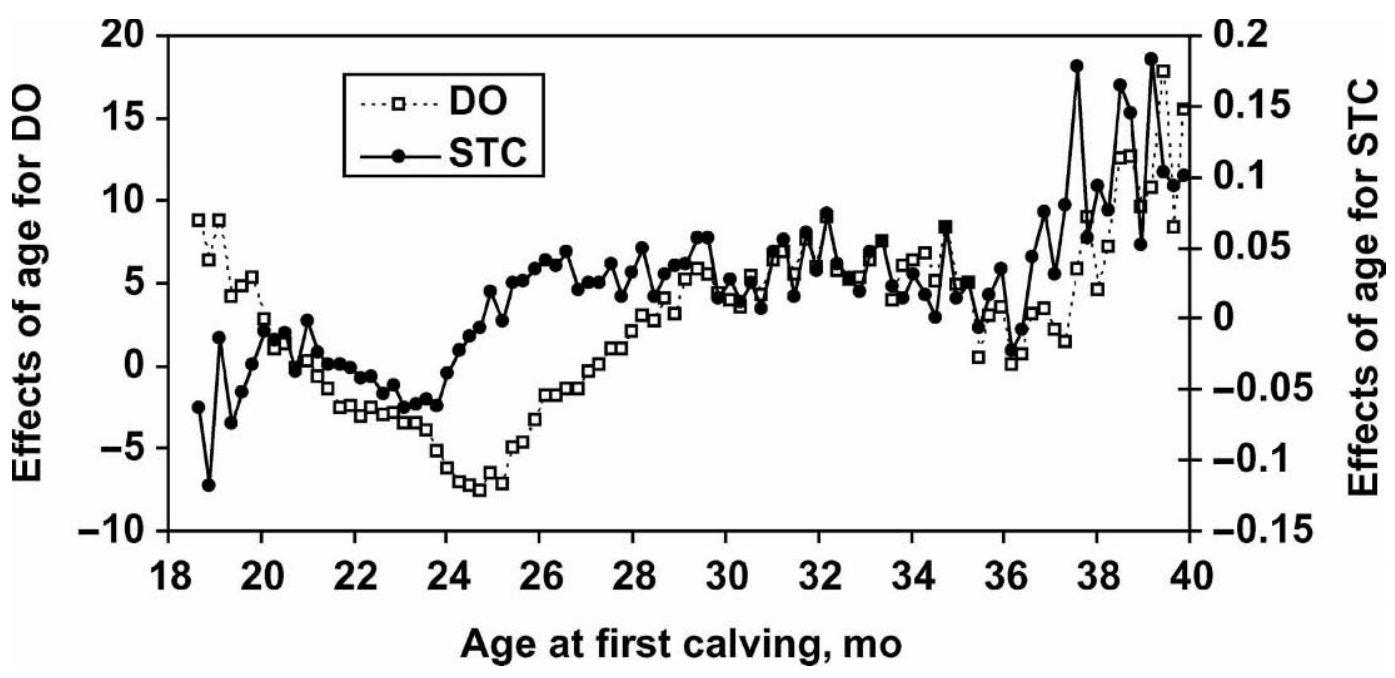

Figure 3. Posterior means of age at first calving effects for number of services to conception (STC) and days open (DO) in first-lactation Norwegian Red cows.

stable between 30 and 37 mo of age at first calving. Younger or older ages at first calving seem to be associated with more DO; and cows tend to have fewer DO when first calving at 25 mo of age. Effects of age at first calving on STC increased somewhat from 20 to 40 mo of age at first calving. These results agree with those in Andersen-Ranberg et al. (2005a), with respect to the pattern of effects of age at calving on 56-d nonreturn rate in first-lactation NRF cows.

The genetic and residual correlations between STC and DO were 0.77 and 0.68 , respectively, which is not surprising because more STC increase DO. Roxström et al. (2001) found a genetic correlation of 0.73 between interval from calving to last insemination and number of inseminations until conception. Genetic correlations between 56-d nonreturn rate and interval from calving to first insemination are much smaller, ranging between 0.05 and 0.24 (Hoekstra et al., 1994; Wall et al., 2003; Andersen-Ranberg et al., 2005a; Jamrozik et al., 2005). Moreover, Jamrozik et al. (2005) found genetic correlations of 0.92 and 0.96 between number of services and intervals from first service to conception for first and later lactation cows, respectively.

Genetic change for STC and DO in first-lactation NRF cows, given as a plot of average sire posterior mean against birth year of daughters is shown in Figure 4 . There has been little or no genetic change for DO, whereas STC shows a decreasing trend. Genetic correlations between nonreturn rate and number of inseminations per conception are between -0.94 and -0.88 (Wall et al., 2003; Jamrozik et al., 2005). AndersenRanberg et al. (2003) found an annual genetic improvement of $0.04 \%$ for 56 -d nonreturn rate in NRF heifers between 1979 and 2000. Because nonreturn rate has been included in the breeding program for NRF since 1974 , the genetic trend for STC is reflecting this correlation between 2 traits.

Presently, STC and DO have not been used in the breeding program for NRF. The censored thresholdlinear model is appealing for predicting breeding values for STC and DO. The censored model takes into account the uncertainty of pregnancy for culled cows, and a bivariate analysis increases the accuracy of the PTA. Research on advantages of including STC in a fertility index together with nonreturn rates is needed to improve genetic evaluation for fertility.

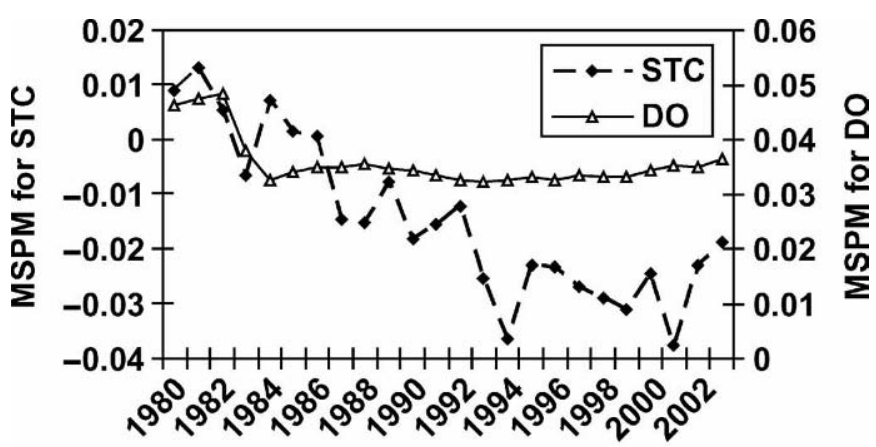

Year of first insemination

Figure 4. Genetic change of number of services to conception (STC) and days open (DO) in first-lactation Norwegian Red cows, given as average sire posterior mean (MSPM) by year of first insemination of daughters. 


\section{CONCLUSIONS}

Number of STC is one of the most important fertility measures, but it has not been used so far in the Norwegian Red breeding program. Methods that take into account censored number of STC could increase the accuracy of inferences about this trait; including STC in a fertility index could improve genetic evaluation for fertility.

\section{ACKNOWLEDGMENTS}

Support from the Wisconsin Agriculture Experiment Station, through the Babcock Institute for International Dairy Research and Development, University of Wisconsin-Madison, and by grants NRICGP/USDA 2003-35205-12833 and NSF DEB-0089742 is acknowledged. Access to the data was given by the Norwegian Dairy Herd Recording System and by the Norwegian Cattle Health Service. GENO Breeding and A. I. Association is acknowledged for providing pedigree information on sires.

\section{REFERENCES}

Albert, J. H., and S. Chib. 1997. Bayesian methods for cumulative, sequential and two-step ordinal data regression models. Technical Report. Department of Mathematics and Statistics, Bowling Green State University, Bowling Green, $\mathrm{OH}$.

Andersen-Ranberg, I. M., B. Heringstad, G. Klemetsdal, M. Svendsen, and T. Steine. 2003. Heifer fertility in Norwegian Dairy Cattle: Variance components and genetic change. J. Dairy Sci. 86:2706-2714.

Andersen-Ranberg, I. M., G. Klemetsdal, B. Heringstad, and T. Steine. 2005a. Heritabilities, genetic correlations, and genetic change for female fertility and protein yield in Norwegian Dairy Cattle. J. Dairy Sci. 88:348-355.

Andersen-Ranberg, I. M., B. Heringstad, D. Gianola, Y. M. Chang, and G. Klemetsdal. 2005b. Comparison between bivariate models for 56-day nonreturn and interval from calving to first insemination in Norwegian Red. J. Dairy Sci. 88:2190-2198.

Averill, T. A., R. Rekaya, and K. Weigel. 2004. Genetic analysis of male and female fertility using longitudinal binary data. J. Dairy Sci. 87:3947-3952.

Boichard, D., and E. Manfredi. 1994. Genetic analysis of conception rate in French Holstein cattle. Acta Agric. Scand. A Anim. Sci. 44:138-145.

Carriquiry, A. L., D. Gianola, and R. L. Fernando. 1987. Mixed model analysis of a censored normal distribution with reference to animal breeding. Biometrics 43:929-939.

Dekkers, J. C. M., J. H. Ten Hag, and A. Weersink. 1998. Economic aspects of persistency of lactation in dairy cattle. Livest. Prod. Sci. 53:237-252.

Dematawewa, C. M. B., and P. J. Berger. 1998. Genetic and phenotypic parameters for 305-day yield, fertility, and survival in Holstein. J. Dairy Sci. 81:2700-2709.

Ducrocq, V., and G. Casella. 1996. A Bayesian analysis of mixed survival models. Genet. Sel. Evol. 28:505-529.

Foulley, J. L., D. Gianola, and R. Thompson. 1983. Prediction of genetic merit from data on binary and quantitative variates with an application to calving difficulty, birth weight and pelvic opening. Genet. Sel. Evol. 15:407-424.
Gianola, D. 1982. Theory and analysis of threshold characters. J. Anim. Sci. 54:1079-1096.

Gianola, D., and J. L. Foulley. 1983. Sire evaluation for ordered categorical data with a threshold model. Genet. Sel. Evol. 15:201-223.

González-Recio, O., and R. Alenda. 2005. Genetic parameters for female fertility traits and a fertility index in Spanish dairy cattle. J. Dairy Sci. 88:3282-3289.

González-Recio, O., Y. M. Chang, D. Gianola, and K. A. Weigel. 2005. Genetic analysis of number of inseminations to conception in Holstein cows using censored records and time-dependent covariates. J. Dairy Sci. 88:3655-3662.

González-Recio, O., M. A. Pérez-Cabal, and R. Alenda. 2004. Economic value of female fertility and its relationship with profit in Spanish dairy cattle. J. Dairy Sci. 87:3053-3061.

Guo, S. F., D. Gianola, R. Rekaya, and T. Short. 2001. Bayesian analysis of lifetime performance in Landrace sows using a linear mixed model with censoring. Livest. Prod. Sci. 72:243-252.

Hoekstra, J., A. W. van der Lugt, J. H. J. van der Werf, and W. Ouweltjes. 1994. Genetic and phenotypic parameters for milk production and fertility traits in upgraded dairy cattle. Livest. Prod. Sci. 40:225-232.

Jamrozik, J., J. Fatehi, G. J. Kistemaker, and L. R. Schaeffer. 2005. Estimates of genetic parameters for Canadian Holstein female reproduction traits. J. Dairy Sci. 88:2199-2208.

Kizilkaya, K., P. Carnier, A. Albera, G. Bittante, and R. J. Tempelman. 2003. Cumulative t-link threshold models for the genetic analysis of calving ease scores. Genet. Sel. Evol. 35:489-512.

Oseni, S., S. Tsuruta, I. Misztal, and R. Rekaya. 2004. Genetic parameters for DO and pregnancy rates in US Holsteins using different editing criteria. J. Dairy Sci. 87:4327-4333.

Raftery, A. E., and S. Lewis. 1992. How many iterations in the Gibbs sampler? Pages 763-774 in Bayesian Statistics 4. J. M. Bernardo, J. O. Berger, A. P. Dawid, and A. F. M. Smith, ed. Oxford University Press, Oxford, UK.

Roxström, A., E. Strandberg, B. Berglund, U. Emanuelson, and J. Philipsson. 2001. Genetic and environmental correlations among female fertility traits and milk production in different parities of Swedish red and white dairy cattle. Acta Agric. Scand. 51:7-14.

Sorensen, D. A., S. Andersen, D. Gianola, and I. Korsgaard. 1995 Bayesian inference in threshold models using Gibbs sampling. Genet. Sel. Evol. 27:229-249.

Sorensen, D. A., D. Gianola, and I. R. Korsgaard. 1998. Bayesian mixed effects model analysis of a censored normal distribution with animal breeding applications. Acta Agric. Scand. 48:222229.

Sorensen, D., and D. Gianola. 2002. Likelihood, Bayesian and MCMC methods in quantitative genetics. Springer-Verlag, New York, NY.

Tempelman, R. J., and D. Gianola. 1999. Genetic analysis of female fertility in dairy cattle using negative binomial mixed models. J. Dairy Sci. 82:1834-1847.

VanRaden, P. M., A. H. Sanders, M. E. Tooker, R. H. Miller, H. D. Norman, M. T. Kuhn, and G. R. Wiggans. 2004. Development of a national genetic evaluation for cow fertility. J. Dairy Sci. 87:2285-2292.

Veerkamp, R. F., E. P. C. Koenen, and G. De Jong. 2001. Genetic correlations among body condition score, yield, and fertility in first-parity cows estimated by random regression models. J. Dairy Sci. 84:2327-2335.

Wall, E., S. Brotherstone, J. A. Woolliams, G. Banos, and M. P. Coffey. 2003. Genetic evaluation of fertility using direct and correlated traits. J. Dairy Sci. 86:4093-4102.

Weigel, K. 2004. Improving the reproductive efficiency of dairy cattle through genetic selection. J. Dairy Sci. 87(E. Suppl.):E86-E92.

Weller, J. I., and E. Ezra. 2004. Genetic analysis of the Israeli Holstein dairy cattle population for production and nonproduction traits with a multitrait animal model. J. Dairy Sci. 87:1519-1527. 